\title{
Implicações éticas na proposição de comportamentos-objetivo a partir da perspectiva behaviorista radical
}

\section{Ethical implications on behavior-goal proposition from the radical behaviorist perspective

\author{
La proposición de comportamientos-gol y aspectos éticos en el Conductismo \\ Radical
}

\author{
Gislayne de Souza Carvalho', Sarah Zuliani da Silva², Nádia Kienen³ ${ }^{3}$ Camila Muchon de Melo4
}

\begin{abstract}
[1-4] Universidade Estadual de Londrina I Título abreviado: Comportamentos-objetivo e Ética Behaviorista | Endereço para correspondência: Departamento de Psicologia Geral e Análise do Comportamento, Centro de Ciências Biológicas, Universidade Estadual de Londrina. Rodovia Celso Garcia Cid, PR 445, Km 380, Campus Universitário. Caixa Postal 10. 011, Cep 86. 057- 970, Londrina, PR. I Email: carvalhogisouza@gmail.com
\end{abstract}

Resumo: O objetivo deste estudo é discutir implicações éticas na proposição de comportamentos-objetivo, pautadas pela filosofia do Behaviorismo Radical. Trabalhos que abordam tecnologias como contribuições da Análise do Comportamento à Educação e que se referem à contextualização do desenvolvimento de uma tecnologia de ensino que teve sua história no Sistema Personalizado de Instrução (PSI) de Keller e atualmente conhecida como "Programação de Condições de Desenvolvimento de Comportamentos" foram selecionados, bem como trabalhos relacionados à ética behaviorista radical. Após a identificação do núcleo da ética behaviorista radical, foi possível estabelecer relações entre essa e a proposição de comportamentos-objetivo considerando qualquer contexto de aprendizagem. Constatou-se que, independente de quem venha a intervir por meio de ensino, esse profissional deve ser capaz de identificar e descrever as contingências que controlam o seu comportamento de propor comportamentos-objetivo e aquelas que controlam o comportamento a ser desenvolvido pelo aprendiz. Tomados esses cuidados, prima-se por questões relevantes à uma ética behaviorista: equilíbrio ao considerar o desenvolvimento do indivíduo e o fortalecimento da cultura da qual ele faz parte, o que favorece o reforçamento de comportamentos tanto na esfera ontogenética quanto cultural. Estabelecer comportamentos relevantes a serem ensinados significa realizar uma avaliação ética preliminar que visa ao benefício da sociedade e do próprio indivíduo que aprende.

Palavras-chave: programação de condições para desenvolvimento de comportamentos, ética, programação de ensino, comportamentos-objetivo, Behaviorismo Radical 
Abstract: The goal of this study is to discuss ethical implications in behaviors-goal proposition, guided by radical behaviorism's philosophy. Studies that approach technology as Analysis of Behavior's contribution for Education and referring to the context of developing an educational technology that had its history in the Personalized System of Instruction (PSI) by Keller and actually known as "Programming of Conditions to Development of Behaviors" were selected as well works related to the radical behaviorist ethics. After identifying the core of the radical behaviorist ethics, it was possible to establish links between that and the goal's behavior proposition considering any learning context. It was found that, regardless of who will intervene through education, these professionals should be able to identify and describe the contingencies that control their behavior to propose behaviors-goal and those that control the behavior to be developed by the learner. Taken such care, press up on relevant issues to one behaviorist ethics: balance when considering the individual's development and culture's strengthening of which it is part, which favors the reinforcement of behaviors both ontogenetic as cultural sphere. Establish relevant behaviors to be taught means to conduct a preliminary ethical evaluation which aims to benefit society and the individual's own learning.

Keywords: programming of conditions to development of behaviors, ethics, programming learning, behaviors-goal, Radical Behaviorism

Resumen: El propósito de este estudio es discutir las implicaciones éticas en la propuesta de comportamientos-objetivo, segundo la filosofía del Conductismo radical. Fueron seleccionados trabajos que tratan tecnologías como contribuciones del Análisis de la Conducta en la Educación y que se refieren a la contextualización del desarrollo de una tecnología de la enseñanza que tuvo sus antecedentes en el Sistema Personalizado de Instrucción (PSI) de Keller y ahora se conoce como "La programación de condiciones de desarrollo de comportamientos", así como trabajos relacionados con la ética conductivista radical. Después de identificar el núcleo de la ética conductivista radical, fue posible establecer relaciones entre esta y la propuesta de comportamientos-objetivo, considerando cualquier contexto de aprendizaje. Se encontró que, independientemente de quien venga a intervenir en la enseñanza, ese profesional debe ser capaz de identificar y describir las contingencias que controlan su comportamiento, proponer comportamientos-objetivo y las que controlan el comportamiento que será desarrollado por el aprendiz. Tomando eses cuidados, se priorizan cuestiones pertinentes a una ética conductivista: equilibrio al considerar el desarrollo del individuo y el fortalecimiento de la cultura a la que pertenece, esto favorece el refuerzo de comportamientos, tanto en la esfera ontogenética cuanto en la esfera cultural. Establecer comportamientos relevantes a ser enseñados significa realizar una evaluación ética preliminar, lo cual ambiciona el beneficio de la sociedad y el del propio individuo que aprende.

Palabras-clave: Programación de condiciones para el desarrollo de las conductas, la ética, la programación de la enseñanza, los comportamientos-objetivo, el Conductivismo radical 
O comportamento como objeto de estudo a partir dos conhecimentos produzidos por B. F. Skinner trouxe características que questionaram modelos tradicionais e mentalistas construídos ao longo do tempo. Skinner criticou teorias que defendiam que o comportamento poderia ser explicado como produto do que era observado por meio da introspecção, assim como teorias criacionistas ou, em tempos mais atuais, das ciências que atribuem essencialmente ao cérebro explicações para o comportamento (Skinner, 1990). A partir da perspectiva skinneriana de explicação, entende-se que o comportamento humano é produto de três tipos de variação e seleção: a primeira delas é a seleção natural (responsável pela evolução da espécie), a segunda diz respeito à ontogênese, explicada a partir do condicionamento operante (que abarca a história de reforçamento ao longo da vida de uma pessoa) e dos comportamentos reflexos condicionais, e a terceira que diz respeito à cultura que ajuda seus membros a manter práticas e solucionar problemas). Sobre ambientes sociais chamados "cultura", "dar modelos, dizer [como as pessoas devem agir] e ensinar" podem ser consideradas algumas de suas funções (Skinner, 1990, p. 1207).

Apesar de a cultura ter um papel importante na função de "ensinar" pessoas, e esse ensinar ocorrer na esfera ontogenética, o "mundo real" não se caracteriza necessariamente como um "professor efetivo". Isso porque a aprendizagem assistemática pode acontecer por meio de "tentativa e erro", o que pode ser insuficiente para ser transmitida como prática cultural, uma vez que tende a se restringir à pessoa submetida a essa experiência, ou no máximo, a uma esfera restrita a quem essa experiência possa ser transmitida. As transmissões das práticas que permitem atuar no mundo de uma forma mais efetiva de acordo com os valores éticos almejados pelo grupo, portanto, parecem ter de ocorrer a partir de um sistema cuidadosamente planejado (Skinner, 1978). Planejar práticas de ensino torna-se, então, relevante para que o indivíduo possa aprender comportamentos importantes ao se relacionar com o grupo.

Ensino pode ser conceituado como um "arranjo de contingências de reforçamento sob as quais os alunos aprendem" (Skinner, 1968/2003, p. 64). Ensinar, portanto, tem como aspecto nuclear de sua definição o fato de alguém ter aprendido em decorrência do fazer de quem ensinou. A partir disso conclui-se que, sem o "efeito" aprendizagem, não é apropriado dizer que alguém ensinou (Kubo \& Botomé, 2001). Aprender, por sua vez, pode acontecer tanto por meio de ensino formal (planejado) quanto por exposição a condições ambientais naturais sem arranjo deliberado de contingências. Mas, o ensino planejado a que Skinner se referiu parece se aproximar mais do que Kubo e Botomé (2001) apontam como uma relação funcional entre o fazer de quem ensina e a mudança no comportamento de quem aprende. A partir dessa concepção, planejar ensino envolve definir quais comportamentos o aprendiz deverá ser capaz de apresentar após o período de ensino (Kubo \& Botomé, 2001). O que acaba por trazer uma outra exigência: definir com precisão esses comportamentos, uma vez que quanto mais precisa a definição dos comportamentos a serem ensinados, maior a probabilidade de esses auxiliarem quem ensina a planejar meios de desenvolvê-los e de avaliar o desempenho de quem aprende ao longo do processo (Kienen, Kubo, \& Botomé, 2013).

Os conhecimentos produzidos pela Análise Experimental do Comportamento (AEC) a partir das décadas de 1930 e 1940 contribuem para tecnologias voltadas aos processos de ensinar e aprender desde o planejamento de condições de ensino adequadas até a identificação e utilização de princípios básicos de aprendizagem que facilitem a condução e a avaliação desses processos. A "Programação de Ensino" como tecnologia derivada da Análise do Comportamento é um dos exemplos. Ela é composta por uma história de aperfeiçoamento conceitual que culmina no que hoje pode ser denominado, de forma mais precisa, de "Programação de Condições para o Desenvolvimento de Comportamentos" (Kienen, Kubo, \& Botomé, 2013).

A partir da década de 1950, Skinner propôs contribuições à Educação, com as máquinas de ensinar (instrumentos nos quais os alunos compunham as respostas e a correção automática e imediata pela máquina indicava seu avanço nos exercícios passo a passo) e a Instrução Programada (material introduzido na máquina de ensinar). Desde então, várias outras contribuições embasadas nos princípios da Análise Experimental do Comportamento surgiram. Dentre elas é possível 
destacar o "Personalized System of Instruction" (PSI), iniciado por Fred Keller e a "Programação de Ensino", desenvolvida no Brasil com o pioneirismo da professora Carolina M. Bori. Fora do Brasil pesquisas em relação à eficiência do uso dos materiais programados continuaram a ser publicadas, como por exemplo, num contexto de ensino por meio de software (Pear \& Crone-Todd, 1999) ou até mesmo em substituição a métodos tradicionais de ensino no sistema geral de ensino de escolas. Escolas dos Estados Unidos e Inglaterra foram planejadas a partir de um sistema organizacional que utilizou o programa $\mathrm{CABAS}^{\circledast}$ (Comprehensive Aplication of Behavior Analysis to Schooling) envolvendo aspectos de aprendizagem dos alunos, professores, supervisores e pais (Twyman, 1998), e reportam o funcionamento de um sistema educacional inspirado pelas ideias de Keller e Greer.

No Brasil, no entanto, desde a década de 1970, surgem uma série de avanços em relação ao processo de programar contingências para desenvolver comportamentos, especialmente a partir das contribuições de Carolina M. Bori e dos trabalhos realizados por vários de seus orientandos (Nale, 1998). A partir disso, ocorre uma mudança no foco do trabalho com ensino programado: de programar materiais didáticos de acordo com princípios da Análise Experimental do Comportamento para descobrir e sistematizar os comportamentos básicos que necessitam ser ensinados por meio desses materiais (Kienen, Kubo, \& Botomé, 2013). Com isso, o que inicialmente passou a ser conhecido como Programação de Ensino passa a ser nomeado de "Programação de Condições para o Desenvolvimento de Comportamentos" (Kienen, Kubo, \& Botomé, 2013), enfatizando os "processos comportamentais que produzem as condições apropriadas para processos de aprendizagem" em lugar da ênfase em apenas seguir ou "aplicar" regras, técnicas e princípios (Kienen, Kubo, \& Botomé, 2013, p. 485). A Programação de Condições para o Desenvolvimento de Comportamentos está de acordo com a proposição de Skinner quanto à necessidade de criar uma tecnologia de ensino que possibilitasse o desenvolvimento de comportamentos de forma programada e coerente com as descobertas feitas no âmbito da Análise Experimental do Comportamento (Skinner, 1968/2003).
Ao se deparar com situações nas quais pode intervir por meio de ensino, o programador (professor ou qualquer pessoa que esteja no papel de ensinar) depara-se com uma pergunta que surge logo no início do processo de planejar condições para desenvolver comportamentos: o que ensinar a esse(s) aprendiz(es)? Essa pergunta relaciona-se à resposta de uma outra pergunta que é mais comum ainda em nosso sistema tradicional de ensino: como ensinar? É justamente a ideia de escolher comportamentos relevantes para serem propostos como objetivos de ensino (como primeira e fundamental tarefa ao programar um curso ou programa de aprendizagem) que se configura como uma das grandes contribuições dos trabalhos de Carolina M. Bori para o desenvolvimento da Programação de Condições para o Desenvolvimento de Comportamentos (Matos, 1998; Nale, 1998).

As principais contribuições de Carolina M. Bori para os trabalhos desenvolvidos sobre Programação de Ensino no Brasil são: (a) preocupação com a proposição de comportamentos-objetivo (o que o aprendiz deve ser capaz de apresentar após o período de ensino), (b) proposição de comportamentos-objetivo como resultado de pesquisa (descoberta de quais comportamentos são relevantes serem ensinados aos aprendizes), (c) alternativa de disposição de contingências de ensino, o que se refere a planejar atividades como recursos para o ensino de comportamentos e (d) planejar procedimentos para o ensino desses comportamentos (Nale, 1998). Nessa nova perspectiva de ensino, abarcava-se as "técnicas" existentes (relacionadas aos materiais programados, utilização de meios imediatos de fornecer feedback, progressão em ritmo individual, etc.) e ampliava-se a possibilidade de planejamento de condições de desenvolvimento de comportamentos, envolvendo, inclusive, o comportamento de quem planeja e o próprio programa na avaliação de todo o processo (Kienen, Kubo, \& Botomé, 2013). Portanto, o material (ou produto) não era o aspecto central no ensino, mas todo o processo envolvendo professor, aluno e as condições programadas a partir de objetivos de ensino propostos.

Objetivos de ensino se referem aos comportamentos que o aprendiz deverá ser capaz de apresentar após o período de ensino (Kienen, 2008) e que deverá resolver (ou atenuar) um problema que ele 
ou a comunidade tem (Kubo \& Botomé, 2001). De forma mais clara e precisa, eles também podem ser chamados de "comportamentos-objetivo" (Botomé, 1980) pois, se os objetivos se referem às aprendizagens a serem apresentadas pelos alunos e se essas aprendizagens se referem a comportamentos, essa pode ser considerada uma expressão mais precisa para nomear o que se pretende ensinar. Diante da proposição clara de comportamentos-objetivo, a tarefa de programar condições de ensino torna-se facilitada e a aprendizagem, entendida como a mudança de comportamento do aprendiz em função do comportamento de quem ensina, é provavelmente mais efetiva. Princípios já descobertos e sistematizados pela Análise do Comportamento auxiliam na tarefa de assegurar a ocorrência da aprendizagem e torná-la mais "fácil" para o aprendiz, como por exemplo: princípio da resposta ativa, progressão em pequenos passos, verificação imediata da adequação da resposta, ritmo individual e teste de avaliação (quando a avaliação do desempenho dos aprendizes é fonte de informação e pode contribuir para o aperfeiçoamento do programa de ensino) (Keller, 1974; Skinner, 1968/2003).

A proposição de comportamentos-objetivo configura-se, então, como a primeira e uma das mais importantes decisões a serem tomadas por quem ensina, uma vez que influenciará todos os demais procedimentos envolvidos com o planejamento de condições de desenvolvimento de comportamentos. Já que, muito provavelmente, (1) a proposição de comportamentos é feita por uma ou mais pessoas que decidem o que outros deverão aprender a partir da realidade na qual vivem, e (2) o ensino do que foi proposto afetará a vida de todos (Skinner, 1978) de alguma forma, programar ensino parece implicar na discussão de uma ética, uma vez que o comportamento intencional de ensinar não é despido de valores (Melo, 2008; Melo, Castro, \& de Rose, 2015). Por isso, ao discutir proposição de comportamentos-objetivo em Programação de Condições para o Desenvolvimento de Comportamentos, faz-se necessário também discutir questões éticas acerca da importância do que será ensinado, da forma como será ensinado, e de quem será beneficiado a partir desse processo de ensino. Questões desse tipo necessitariam invariavelmente permear as ações do analista do comportamento em sua atuação profissional, que deveria sempre pensar o indivíduo e/em sua cultura.

O objetivo deste manuscrito consiste em elucidar discussões relacionadas à ética behaviorista radical no processo de programar condições para o desenvolvimento de comportamentos, em que são discutidas implicações éticas na proposição de comportamentos-objetivo a partir da literatura em Programação de Ensino e sobre a ética behaviorista. A fim de elucidar tais questões, foram selecionados textos clássicos de autores nacionais e estrangeiros sobre as temáticas "Programação de Ensino" e "Ética behaviorista radical", como Skinner, Keller e Carolina M. Bori. Ou seja, textos que são considerados principais em uma análise teórica-conceitual por se tratarem de obras que propõem uma teoria, neste caso, o Behaviorismo Radical na sua relação com a Ética e a Educação. A partir da adequação dos textos em relação ao objetivo deste trabalho, foram selecionados textos auxiliares de autores que prosseguiram estudando e comentando sobre os temas, sem delimitação de período de publicação. Assim, a escolha dos textos principais e auxiliares foi baseada em uma reconstrução lógica e crítica dos argumentos que fundamentam o tema. Os textos utilizados como fonte de obtenção de dados compuseram o material de apoio para relacionar essas duas temáticas a partir da Análise do Comportamento, o que permitiu avaliar implicações éticas na proposição de comportamentos-objetivo em intervenções por meio de ensino.

\section{Revisitando a História da Programação de Ensino}

Fred Keller (professor e amigo pessoal de Skinner) juntamente com outros pesquisadores, psicólogos e assessores norte-americanos perceberam que a escola e o método tradicional de ensino estavam ultrapassados em relação ao que se poderia fazer a partir de conhecimentos já produzidos pela Ciência do Comportamento de fundamentação behaviorista radical. Utilizar o reforçamento imediato, segundo a visão deles, seria uma das principais e mais práticas contribuições a beneficiarem a eficiência do ensino (Keller, 1968, 1974).

Ao atuar no treinamento inicial de código morse dado a membros do Corpo de Sinalização 
nos Estados Unidos, na Segunda Guerra Mundial, em que a instrução era altamente individualizada (apesar do número de pessoas), o sistema de ensino de Keller envolvia algumas características: os alunos avançavam em seu próprio ritmo, a instrução era planejada em etapas escalonadas em relação ao objetivo final, havia redução de aulas expositivas, utilização de monitores, dentre outras (1968). Keller argumentou, então, que esse sistema poderia ser ampliado a outros contextos como ao de educação universitária, por exemplo, aumentando assim a eficiência do ensino da forma mais personalizada possível.

O Sistema Personalizado de Ensino (PSI) chegou ao Brasil por meio de Keller em 1962 quando, juntamente com Sherman e dois psicólogos brasileiros (Carolina M. Bori e Rodolpho Azzi), planejaram e efetivaram o ensino de uma disciplina de Psicologia Experimental na Universidade de São Paulo (USP). Eles foram também convidados a organizar um Departamento de Psicologia na recém construída Universidade de Brasília (UnB) (Keller, 1968, 1974), o que deu margem a questionamentos em relação ao ensino e também ao surgimento de novas linhas de pesquisa em universidades do país. Com um projeto piloto utilizando de todo o conhecimento sobre ensino programado até aquele momento, tiveram liberdade de planejar como o curso seria conduzido. O início dos trabalhos na UnB foi interrompido em função do golpe militar e da ditadura no Brasil, atrasando a inauguração de tudo o que havia sido programado. Considerando a década de 1960, eventos notáveis aconteceram no Brasil com efeitos perceptíveis em relação à educação, como o Método de Alfabetização de Adultos de Paulo Freire, e o de Carolina M. Bori com Programação de Condições de Ensino. O reflexo do método de Paulo Freire foi de derivar "o que" ensinar orientando o ensino para objetivos que promovessem transformação social; já o de Carolina Bori diz respeito a tornar o ensino mais científico e relevante, a partir da articulação entre as necessidades sociais do aprendiz e as descobertas da ciência (Kubo \& Botomé, 2001).

Na década de 1960, alguns preceitos já conhecidos pela Análise do Comportamento eram utilizados em alguns contextos, como a participação ativa do aluno, o respeito ao ritmo individual, a aprendizagem em pequenas etapas e a consequenciação imediata. Além disso, aperfeiçoamento em conceitos relacionados aos processos de ensinar e aprender passaram a ser desenvolvidos (Keller, 1968, 1974). Concomitante a isso, proliferava-se a literatura em relação a objetivos de ensino (Kienen, 2008), a como proceder com o "ensino programado", a livros sobre objetivos comportamentais e também a críticas e avaliações ao que foi chamado de "tecnologia de ensino" ou "tecnologia comportamental do ensino", alertando para os riscos do uso dessa tecnologia (Kubo \& Botomé, 2001). Com o passar do tempo, reformulações e avanços aconteceram, e o próprio nome do que antes fora conhecido por "Ensino Programado" foi alterado para "Programação de Ensino" e, mais recentemente, para "Programação de Condições para o Desenvolvimento de Comportamentos" (Kienen, Kubo, \& Botomé, 2013), enfatizando a complexidade do processo de planejar e desenvolver comportamentos.

À semelhança do raciocínio de Holland (1978) sobre o papel do comportamentalismo em uma sociedade estratificada com interesses conflitantes, é possível pensar que a própria tecnologia de ensino passou a ser parte do problema, e não apenas da solução. No PSI, o material a ser elaborado como meio para desenvolver aprendizagens parecia ser a solução para problemas educacionais, contudo, permanecia o problema de definir o que ensinar para capacitar o aprendiz a transformar a realidade com a qual se depararia depois do período de ensino. Isso porque a tecnologia não poderia mais ser concebida como uma técnica a ser aplicada a um problema de ordem prática, mas que requeria uma complexa análise para verificar o que precisaria ser ensinado, assim como quais seriam os melhores caminhos (não no sentido de julgamento, mas referindo-se à eficácia) para realizar o trabalho de desenvolver comportamentos-objetivo. A escolha de comportamentos relevantes para serem propostos como objetivos de ensino é a primeira e fundamental tarefa para programar um curso (Nale, 1998). Os objetivos propostos no curso necessitam representar uma classe de comportamentos que tenha valor tanto a quem está sendo ensinado, quanto para a sociedade na qual o aprendiz irá atuar (Botomé \& Kubo, 2002). Espera-se que quem exerça a função 
de "ensinar" seja capaz de identificar situações em que aquele que está "aprendendo" se comporte de determinadas maneiras para propor comportamentos que vão ao encontro dessas situações do ambiente natural do aprendiz (Botomé \& Kubo, 2002).

Termos como "conhecimento", "ensinar", "aprender" e "comportamentos-objetivo" necessitam estar operacionalizados a fim de que seja possível identificar com maior precisão e clareza a que eles se referem. O "conhecimento" ou as "informações" constituem meios para o processo de aprendizagem, enquanto a capacidade de atuar (aptidões, competências ou habilidades) constituiria o resultado desse processo. $\mathrm{O}$ grande desafio do processo de ensino é tornar o aprendiz capacitado a transformar o conhecimento em capacidade de atuar (Botomé \& Kubo, 2002). Nesse sentido, o conhecimento não é algo pronto a ser transmitido, nem tampouco se refere a um objetivo de ensino, mas à matéria-prima a partir da qual quem ensina (professor, terapeuta, etc.) planeja e executa condições que resultam em uma "capacidade de atuar". Essa capacidade de atuar constitui os comportamentos-objetivo, ou seja, são as aprendizagens a serem apresentadas pelos aprendizes. Transformar conhecimento em capacidade de atuar é mais complexo do que pode parecer, envolvendo tomadas de decisão ao longo de um processo que é fluido e pode ser aperfeiçoado enquanto está sendo operacionalizado, a partir da observação dos efeitos no repertório do aprendiz.

Diversos pesquisadores, em variados contextos de atuação, têm se dedicado à descoberta de comportamentos-objetivo constituintes de diferentes funções ou atuações profissionais na sociedade. A exemplo disso pode-se citar trabalhos relacionados à educação (Kawasaki, 2013; Luiz, 2013), à formação profissional do psicólogo (Kienen, 2008; Viecili, 2008); à interação parental (Teixeira, 2010), à avaliação da confiabilidade de informações (De Luca, 2013), dentre outros que contribuem para a produção e sistematização sobre capacidades importantes a serem desenvolvidas para que o aprendiz se relacione com sua comunidade verbal de forma mais eficaz. A complexidade e quantidade de comportamentos requeridos de quem intervém por meio de ensino, por exemplo, podem ser identificadas na tese de
Kienen (2008). A partir de um processo de derivação de comportamentos da literatura e de um método de decomposição de comportamentos, a autora encontrou mais de 700 comportamentos relacionados à classe geral "intervir, por meio de ensino, sobre fenômenos e processos psicológicos", que é uma das capacidades esperadas de um psicólogo. Uma das classes que compõe esse comportamento é "propor comportamentos-objetivo de programas de aprendizagem". Portanto, tanto para psicólogos, quanto para professores ou para quaisquer outros profissionais que venham a intervir, por meio de ensino, é importante que esses tenham claro quais comportamentos seu aprendiz deve ser capaz de apresentar diante de situações em que ensinar seja necessário.

Partindo do pressuposto de que estabelecer comportamentos-objetivo é também comportamento de alguém que, a partir de uma análise complexa do ambiente decide ensinar determinados comportamentos e não outros, podem surgir algumas perguntas: definir quais comportamentos serão ensinados é passível de uma discussão ética? Os que exercem a função de estabelecer comportamentos-objetivo poderiam fazê-lo vinculado a valores pessoais ou sociais? Se sim, quais os possíveis impactos disso na vida de quem aprende? Estaria o comportamento do aprendiz em função de variáveis as quais não tem acesso? Quanto estabelecer comportamentos-objetivo controlado por variáveis específicas pode sofrer influência dos próprios valores de quem ensina?

Portanto, tais questionamentos revelam que falar de programação de condições de ensino, aqui entendida como um processo comportamental com a finalidade de desenvolver comportamentos pré-estabelecidos, é também falar de ética e da produção de um bem para o indivíduo em determinada cultura. Alguns aspectos da filosofia moral e da ética skinneriana são importantes para tal, bem como sua utilização prática que norteia analistas do comportamento no desenvolvimento de tecnologias de ensino e também em sua atuação, seja na clínica ou no ensino de comportamentos em qualquer outro contexto. 


\section{A Ética Behaviorista Radical e a Prática dos Analistas do Comportamento}

Falar de um sistema ético skinneriano é também falar do modelo de seleção do comportamento por consequências, que é compreendido a partir dos três níveis de seleção. O sistema ético skinneriano descreve três tipos de bens: os bens pessoais (reforçadores positivos produzidos pelo próprio indivíduo), os bens dos outros (reforçadores produzidos por um indivíduo, mas que reforçam o comportamento de outros) e os bens das culturas (consequências de práticas que promovem a sobrevivência das culturas) (Dittrich \& Abib, 2004). Sendo assim, o comportamento considerado "ético" produz ao menos um desses bens ou mais de um, concomitantemente.

Além disso, é possível notar algumas peculiaridades existentes no sistema ético skinneriano que são norteadas pelo modelo de seleção do comportamento por consequências. Bens pessoais incluiriam tanto reforçadores primários quanto secundários. São considerados primários os reforçadores imediatos ou incondicionais que promovem a sobrevivência da espécie - como alimento, sexo e segurança, por exemplo. Já os reforçadores secundários seriam todos aqueles que derivam dos primários e, portanto, são condicionais. Bens dos outros seriam produzidos via comportamento operante (dessa forma, o reforçamento recíproco é que mantém o agir para o bem do outro) e bens culturais são produzidos quando práticas culturais são selecionadas à medida que promovem a sobrevivência e a perpetuação da cultura que as mantêm (Abib, 2001, Dittrich \& Abib, 2004).

Há que se atentar ao fato de que, ao indicar tais comportamentos e consequências como "bons", Skinner não se refere a julgamentos pessoais, tampouco aponta-os como ideais para a sobrevivência de uma cultura ou espécie, mas está descrevendo contingências. Isso quer dizer que uma prática cultural que promove a sobrevivência de uma cultura será selecionada independentemente da "vontade" do indivíduo, assim como práticas culturais que não promovam a sobrevivência de uma cultura poderiam contribuir para a sua extinção. $\mathrm{O}$ que não significa afirmar que o "ético" ou "bom" predomine sobre o "antiético" ou "ruim". Isso ocorre porque, através do processo evolutivo em seu caráter móvel, aquilo que é considerado bom em determinado contexto pode ser considerado ruim em outro contexto. E essa mobilidade é determinada pelo comportamento do próprio organismo e das práticas culturais de atribuição de valores (Dittrich \& Abib, 2004) que, ao modificarem-se, modificam também o ambiente, tornando difícil a tarefa de criar regras ou classificações inflexíveis para ações que se transformam juntamente com a cultura. Seria, então, pertinente falar sobre decisões éticas, que devem ser avaliadas ao longo do tempo, levando em consideração o contexto em que o comportamento ocorre, a despeito de um conjunto estático de regras e que não pode acompanhar a mobilidade do processo evolutivo comportamental e cultural.

A filosofia moral skinneriana, por sua vez, apresenta-se em dois aspectos: descritivo e prescritivo. $\mathrm{O}$ aspecto descritivo trata da ciência dos valores, do estudo do comportamento ético, da explicação em três níveis de seleção, do porquê os indivíduos se comportam eticamente, falam sobre ética ou promovem certos valores em detrimento de outros. Existe aqui, a descrição do comportamento ético, bem como das variáveis que o controlam. Já o aspecto prescritivo dessa filosofia trata de um mando, ou uma prescrição de um valor que Skinner aponta como fundamental, a sobrevivência da cultura e, sendo os demais valores, subordinados a ela (Dittrich \& Abib, 2004; Dittrich, 2006). Para os autores, a sobrevivência das culturas continuará como um critério de seleção independentemente de nossa vontade, porém, justamente por tratar-se de um aspecto prescritivo, isso não obriga analistas do comportamento a elegê-la como diretriz ética fundamental, pois uma "ciência dos valores não pode justificar a opção ética pela sobrevivência das culturas - ou, pelo menos, não pode colocá-la como um princípio científico" embora seja ele criado a partir de uma ciência dos valores (Dittrich \& Abib, 2004, nossas ênfases). Sendo assim, uma ética skinneriana não dita padrões específicos de valores secundários. Com exceção da sobrevivência das culturas (apontada por Skinner como valor fundamental), a ética behaviorista radical é plástica, móvel e adapta-se aos mais diferentes contextos a fim de promover a sobrevivência das culturas. Além disso, 
Skinner não apresenta em sua ética uma distinção ontológica entre fatos e valores, ambos podem ser analisados como função de variáveis ambientais (Leigland, 2005).

Tendo Skinner prescrito apenas um valor fundamental para embasar sua filosofia moral e, justamente, por tratar-se de uma prescrição, é controverso assumir tal filosofia com um aval de cientificidade. É, então, perfeitamente possível - e coerente - que analistas do comportamento discordem quanto aos seus critérios de valor e tenham, portanto, práticas distintas - ou até mesmo opostas - ao eleger seu embasamento ético e moral (Dittrich \& Abib, 2004; Dittrich, 2006). Sendo assim, quais os possíveis critérios de ação ao adotar-se uma ética skinneriana, móvel e adaptável (aos mais diferentes contextos) como valor que norteará a ação? Se num processo de programar condições para desenvolver comportamentos em qualquer contexto, quem decide o que ensinar deve fazê-lo com base nos interesses da "comunidade" e do "aprendiz" (Botomé \& Kubo, 2001), poderia haver divergência entre as necessidades da comunidade, do aprendiz, de quem está propondo os comportamentos-objetivo e, por fim, de quem vai ensinar? Estariam essas "necessidades" de aprendizagem alinhadas entre si?

Aponta-se então, como um caminho, a possibilidade de uma ética que seja conciliadora entre o sujeito e/ou a comunidade e o educador (Dittrich \& Abib, 2004). Pois, uma vez que o analista do comportamento não possui o mesmo conhecimento que o sujeito e/ou a comunidade que está sob controle das contingências de intervenção, há que se agir de forma colaborativa, submetendo os critérios éticos do educador ou cientista à aprovação do sujeito ou comunidade que são objeto de sua análise e intervenção. Isso se justifica à medida que o sujeito da intervenção, provavelmente, não aprovaria uma ética apontada pelo analista do comportamento se ela fosse oposta ou muito diferente de sua ética pessoal. Para os autores, tal consenso seria o ideal e não seria impossível colocá-lo em prática, uma vez que tanto o profissional quanto seu sujeito em análise podem apresentar critérios secundários semelhantes como critérios de valor (tais como felicidade, saúde, segurança, produtividade, amor, cooperação e apoio mútuo, preservação do meio ambiente etc.). Sendo assim, utilizá-los como curso de ação para atingir o objetivo final de promover a sobrevivência das culturas, ou a sobrevivência ou adaptabilidade de um sujeito em sua cultura por meio de ensino, seria uma alternativa plausível e coerente com os pressupostos behavioristas radicais. Apesar de o educador ou a pessoa que exerce o papel de atuar com base no conhecimento científico terem conhecimento mais profundo acerca de tecnologias e conceitos relacionados ao ensino, ambos fazem parte de uma comunidade social que se parece em aspectos básicos. Espera-se, então, que tais valores, em sua maioria, possam aparecer em concomitância.

Skinner apresentou preocupação quanto a um equilíbrio entre o bem do indivíduo e de sua cultura, exercido pelo próprio psicólogo comportamental, o que sugere que, em certos momentos, onde há um controle aversivo da sociedade sobre o indivíduo, há que se desenvolver comportamentos de contra-controle, bem como a aceitação dessas agências controladoras por parte do indivíduo que deve, ao fim de uma intervenção (condição de ensino em um ambiente específico), estar mais bem adaptado à sua cultura (Melo, 2008). Dessa forma, em um planejamento ético, favorecer o bem do indivíduo em seu grupo é também favorecer o bem da cultura. Ao estabelecer comportamentos-objetivo que visem ao desenvolvimento do indivíduo em um determinado contexto (terapêutico, escolar, organizacional ou profissional), desenvolve-se também a capacidade deste se comportar de maneira mais efetiva no grupo social do qual faz parte, uma vez que, para Skinner (1978), uma cultura que se preocupa com sua sobrevivência tem mais chance de atingir seu objetivo (de sobreviver).

Outro caminho possível se refere a uma ética que seja adequada ao contexto específico de cada relação de intervenção (Vandenberghe, 2005). Sendo assim, faz-se necessário analisar os diferentes contextos de inserção social do indivíduo para que se possa decidir qual a melhor intervenção para um determinado aprendiz, considerando-se, assim, que o analista do comportamento possui condições suficientes de análise para identificar as contingências que controlam tanto o comportamento do aprendiz quanto o próprio comportamento durante as intervenções, como produto de uma cultura e como alvo de possíveis julgamentos da sociedade. 
Carolina M. Bori enfatizou que o comportamento-objetivo deveria fazer sentido à vida da pessoa "seja como profissional, seja como cidadão" (Nale, 1998, p. 3), preocupando-se profundamente com problemas sociais. Dessa forma, o programador de ensino (professor, terapeuta, capacitador etc.) também tem a responsabilidade de decidir o que pretende com aquilo que está sendo ensinado e deve perguntar a si mesmo: quais os possíveis impactos sociais de formar indivíduos com as características desenvolvidas na aprendizagem desses comportamentos-objetivo propostos? Estarei eu desenvolvendo comportamentos que contribuem para a sobrevivência da espécie? Os comportamentos-objetivo desenvolvidos trazem benefícios para o aprendiz e também para a cultura da qual ele faz parte sem trazer danos a outras culturas?

É importante ressaltar que os comportamentos classificados como bons e maus não são atribuídos à bondade ou à maldade em si, mas aos agentes reforçadores presentes no contexto social, e à comunidade, que lança mão de reforçadores verbais como: “bom!”, “mau!", “certo!” e "errado" (Skinner, 1971). Nesse sentido, a ética skinneriana sugere que a própria comunidade dite seus critérios de valor, de comportamentos que serão avaliados por ela como bons ou ruins (Ruiz \& Roche, 2007; Skinner, 1971). Porém, como dito por Melo (2015), uma das desvantagens em adotar a sobrevivência da cultura como valor fundamental, está no fato de que uma das funções desempenhadas por ela seria a competição entre culturas. A autora exemplifica esse impasse fazendo referência a períodos históricos em que, além da competição entre culturas, há também a destruição de uma pela outra. Como exemplos, podem ser citados os períodos de escravidão e os poucos resquícios culturais indígenas que sobreviveram enquanto práticas culturais brasileiras. Neste sentido, o bem da cultura como valor fundamental em uma ética prescritiva não responde à questão de qual cultura é meta para o planejamento.

Contudo, isso não quer dizer que o modelo skinneriano de seleção por consequências não possa fundamentar nossas discussões e debates éticos, ao contrário, como afirma Dittrich (2008), a ciência skinneriana não pode justificar a adoção ou predileção absoluta de nenhum valor em detrimento de outro, uma vez que a adoção de um posiciona- mento acerca de valores é, aqui, explicada por meio de uma história idiossincrática do comportamento humano (ver também Chiesa, 2003). Entretanto, uma análise adequada de consequências pode ser muito útil para fomentar a tomada de decisões éticas (Dittrich, 2010). De acordo com o autor, decisões éticas implicam a previsão de consequências.

Para auxiliar nesse processo, Dittrich (2010) sugere quatro etapas para analisar essas consequências, que, no presente estudo, serão exemplificadas com base na Programação de Condições para o Desenvolvimento de Comportamentos. São elas: (1) categorização de consequências, que consistiria em prever quais as possíveis consequências de ensinar o que se propõe; (2) definição de pessoas ou grupos afetados, que compreende a identificação de todas as pessoas que serão afetadas pelo ensino (alunos, familiares, instituições); (3) definição dos efeitos seletivos das consequências, que aborda o efeito das contingências de ensino estabelecidas para o comportamento do aprendiz, podendo alterar a forma e a frequência desse comportamento; por fim, a (4) definição da sequência temporal das consequências, que trata do fato de que aquilo que é feito no presente possui consequências que se estendem pelo futuro, dessa forma, deve-se refletir se as consequências produzidas pela aprendizagem têm efeito imediato ou se trazem contribuições em longo prazo para a vida do aprendiz e da comunidade em que está inserido.

\section{Considerações Finais}

Ensinar comportamentos ou programar condições para o desenvolvimento desses é também se comportar sob produto de contingências. Analisar as contingências que determinam o comportamento daquele que ensina é fundamental para que seja possível compreender e intervir de forma eficaz para o desenvolvimento de qualquer comportamento que se pretende ensinar. A escolha ou decisão de quais comportamentos desenvolver deve estar em consonância com o que é "bom" tanto para o indivíduo quanto para o meio do qual ele faz parte, sem que isso implique também danos a outras comunidades ou culturas.

Definir comportamentos-objetivo no processo de ensino implica em uma discussão ética acerca 
do que será ensinado, bem como de sua importância. Nesse sentido, um ensino eficaz necessita, em última instância, favorecer o fortalecimento da cultura na qual o indivíduo está inserido, em equilíbrio com o seu bem-estar (Melo, 2008). Não seria nem um extremo, nem o outro, mas uma análise em que se pretende convergir ambos os interesses para um equilíbrio, a fim de que o indivíduo tenha seu comportamento reforçado tanto na esfera ontogenética, quanto na esfera cultural e que a cultura se fortaleça.

Sugere-se, então, uma ética behaviorista da mobilidade, contextualista, colaborativa e que busca conciliar a sobrevivência da humanidade com seus bens e valores individuais (Ruiz \& Roche, 2007), nesse sentido, o bem da cultura transforma-se no bem das culturas. Assim, pode-se concluir que ao ensinar comportamentos, é fundamental levar em conta aspectos da inserção social daquele que aprende. O bem individual do aprendiz deve favorecer o bem do grupo ao qual ele pertence buscando o equilíbrio "indivíduo" versus "sociedade" que, ainda que complexo, necessita ser almejado. Os comportamentos-objetivo devem, portanto, ser importantes para o indivíduo em seu contexto cultural e social (Kubo \& Botomé, 2001) e não apenas fazer sentido no contexto do ensino propriamente dito (Nale, 1998).

Assim como a Programação de Condições de Desenvolvimento de Comportamentos no Brasil teve suas origens em meados da década de 1960 (relativamente recente em termos de história) por esforços de pessoas que foram sensíveis a mudanças em determinados contextos (naquele caso educacionais), muitos avanços vêm acontecendo na medida em que novas demandas sociais emergem. Isso favorece tanto o fomento do comportamento do cientista de buscar relações entre eventos, quanto de desenvolver tecnologia adequada para "acessar" tais fenômenos. Dado que o comportamento humano não é estático, mas fluido, evanescente e não pode ser completamente imobilizado para ser estudado (Skinner 1953/1998), recortes necessariamente devem ser feitos para que uma análise funcional (e didática) seja permitida. Espera-se, ainda, que os analistas do comportamento, bem como pessoas que exerçam o papel de "ensinar", "programar ensino", "desenvolver comportamento", ao menos con- sigam identificar quais variáveis devem ser levadas em conta no processo de propor comportamentos-objetivo para desenvolvê-los em repertórios cada vez mais alinhados com o meio social dos sujeitos e da própria humanidade.

Sobre a tomada de decisões éticas acerca do que e de como ensinar, faz-se necessário ressaltar a importância de que a análise de consequências do processo de ensino-aprendizagem aconteça de forma democrática, não arbitrária, para que todos os alunos e pessoas envolvidas diretamente pelo ensino possam auxiliar. A manifestação dos envolvidos é importante porque assegura que as consequências, que porventura tenham sido esquecidas durante a análise, possam ser identificadas, e para que cada indivíduo, a partir de sua história singular de reforçamento, possa explicitar o valor que atribui às consequências previstas pelo capacitador (Carrara et al., 2013, Dittrich, 2010).

Em última análise, programar condições de ensino é comportamento operante que necessita estar sensível às contingências que determinam o comportamento do aprendiz, seu meio social, bem como às próprias variáveis que estão em relação com o comportamento de quem está ensinando. Primando, assim, pelo respeito aos valores éticos culturais e visando ao "bem" e à ética em que prevaleça, além do interesse individual, o interesse do grupo e da humanidade.

\section{Referências}

Abib, J. A. D. (2001). Teoria moral de Skinner e desenvolvimento humano. Psicologia: Reflexão e Crítica, 14 (1), 107-117. doi: 10.1590/S010279722001000100009

Botomé, S. P. (1980). Objetivos comportamentais no ensino: A contribuição da análise experimental do comportamento. (Tese de Doutorado não publicada). Universidade de São Paulo, São Paulo.

Botomé, S.P., \& Kubo, O.M. (2002). Responsabilidade social dos programas de pós-graduação e formação de novos cientistas e professores de nível superior. Interação em Psicologia, 6 (1), 81-110. doi: 10.5380/psi. v6il.3196

Carrara, K., de Souza, V. B., Oliveira, D. R., Orti, N. P., Lourencetti, L. A., \& Lopes, F. R (2013). 
Desenvolvimento de guia e fluxograma como suporte para delineamentos culturais. Acta Comportamentalia, 21 (1), 99-119.

Chiesa, M. (2003). Sobre la meta-ética, la ética normativa y el conductismo. Revista Latinoamericana de Psicologia, 35 (3), 289-297.

De Luca, G. G. (2013). Avaliação da eficácia de um programa de contingências para desenvolver comportamentos constituintes da classe geral "Avaliar a confiabilidade de informações". (Tese de doutorado). Recuperado de https://repositorio.ufsc.br/handle/123456789/122722

Dittrich, A., \& Abib. J. A. D. (2004). O sistema ético skinneriano e conseqüências para a prática dos analistas do comportamento. Psicologia: Reflexão e Crítica, 17, 427-433. doi: 10.1590/ S0102-79722004000300014

Dittrich, A. (2006). A sobrevivência das culturas é suficiente enquanto valor na ética behaviorista radical? In H. J. Guilhardi e N. C. de Aguirre (Orgs.). Sobre comportamento e cognição: Expondo a variabilidade (V. 17, pp. 11-22). Santo André, SP: ESETec.

Dittrich, A. (2008). O problema da "justificação racional de valores" na filosofia moral skinneriana. Revista Psicologia, 1, 21-26.

Dittrich, A. (2010). Análise de consequências como procedimento para decisões éticas. Perspectivas em Análise do Comportamento, 1(1), 44-54.

Holland, J. G. (1978). Behaviorism: Part of the problem or part of the solution? Journal of Applied Behavior Analysis, 11, 163-174.

Kawasaki, H. N. (2013). Avaliação da eficiência de um programa de contingências para desenvolvimento de comportamentos da classe "caracterizar comportamentos-objetivo" a profissionais de uma organização não-governamental do campo da educação. (Dissertação de mestrado). Recuperado de https://repositorio.ufsc.br/ xmlui/handle/123456789/123011.

Keller, F. (1968). Good-bye, teacher. Journal of Applyed Behavior Analysis, 1, 79-89. doi: 10.1901/jaba.1968.1-79

Keller, F. S. (1974). The history of PSI. In F.S. Keller, \& J.G. Sherman (Eds.). The Keller Plan Handbook (pp.6-13). Georgetown University: W. A. Benjamin Publishers.

Kienen, N. (2008). Classes de comportamentos pro- fissionais do psicólogo para intervir, por meio de ensino, sobre fenômenos e processos psicológicos, derivadas a partir das diretrizes curriculares, da formação desse profissional e de um procedimento de decomposição de comportamentos complexos. (Tese de Doutorado). Recuperado de http://repositorio.ufsc.br/xmlui/handle/123456789/92016

Kienen, N., Kubo, O. M., \& Botomé, S. P. (2013). Ensino programado e programação de condições para o desenvolvimento de comportamentos: Alguns aspectos no desenvolvimento de um campo de atuação do psicólogo. Acta Comportamentalia, 21 (4), 481-494.

Kubo, O. M., \& Botomé, S.P. (2001) Ensinoaprendizagem: Uma interação entre dois processos comportamentais. Interação, 5, 133-170. doi: $10.5380 /$ psi.v5i1.332

Leigland, S. (2005). Variables of which values are a function. The Behavior Analyst, 28, 133-142.

Luiz, F. B. (2013). Classes de comportamentos-objetivo de aprendizagem de história derivadas de documentos oficiais. (Dissertação de Mestrado). Recuperado de https://repositorio.ufsc.br/ xmlui/handle/123456789/123147

Matos, M. A. (1998). Carolina Bori: A Psicologia Brasileira como Missão. Psicologia USP, 9 (1), 67-70. doi: 10.1590/S0103-65641998000100009

Melo, C. M. (2008). A concepção de homem no behaviorismo radical e suas implicações para a tecnologia do comportamento. (Tese de doutorado). Recuperado de http://www.dfmc.ufscar.br/ uploads/publications/4f048aaadc706.pdf

Melo, C. M. (2015). Análise comportamental da cultura e implicações para a saúde. In C. S. M. Bandini, L. M. M. Postalli, L. P. de Araújo et al. (Orgs). Compreendendo a prática do analista do comportamento (177p.) São Carlos: EdUFSCar.

Melo, C. M., Castro, M. S. L. B, \& De Rose (2015). Some relations between culture, ethics and technology in B. F. Skinner. Behavior and Social Issues, 24, 39-55. doi:10.5210/bsi.v.22i0.4207

Nale, N. (1998). Programação de ensino no Brasil: O papel de Carolina Bori. Psicologia USP, 9 (1), 275-301. doi: 10.1590/S010365641998000100058

Pear, J. J. P., Crone-Todd, D. E (1999). Personalized system of instruction in cyberspace. Journal of 
Applied Behavior Analysis, 32(2), 205-209. doi: 10.1901/jaba.1999.32-205

Ruiz, M. R. \& Roche, B. (2007). Values and the scientific culture of behavior analysis. The Behavior Analyst, 30 (1), 1-16.

Skinner, B. F. (1971). Beyond freedom and dignity. New York, NY: Alfred A. Knopf.

Skinner, B. F. (1978) Reflexions on Behaviorism and Society. Englewod Cliffs, NJ: Prentice-Hall.

Skinner, B. F. (1990). Can Psychology be a science of mind? American Psychologist, 45(11), 12061210. doi:10.1037/0003- 066X.45.11.1206

Skinner, B. F. (1998). Ciência e comportamento humano. (J. C. Todorov \& R. Azzi, Trads.). São Paulo: Martins Fontes. (Texto original publicado em 1953).

Skinner, B. F. (2003). The technology of teaching. Cambridge, MA: B. F. Skinner Foundation. (Trabalho original publicado em 1968).

Teixeira, F. C. (2010). Avaliação da eficácia de um programa para ensinar pais a analisar $e$ sintetizar comportamentos na interação com seus filhos. (Tese de Doutorado). Recuperado de https://repositorio.ufsc.br/xmlui/handle/123456789/94390

Twyman, J. S. (1998). The Fred S. Keller school. Journal of Applied Behavior Analysis, 31, (4), 695- 701. doi: http://dx.doi.org/10.1901/ jaba.1998.31-695

Viecili, J. (2008). Classes de comportamentos profissionais que compõem a formação do psicólogo para intervir por meio de pesquisa sobre fenômenos psicológicos, derivadas a partir das diretrizes curriculares nacionais para cursos de graduação em psicologia e da formação desse profissional. (Tese de Doutorado). Recuperado de https:// repositorio.ufsc.br/handle/123456789/91417

Vandenberghe, L. (2005). Uma ética behaviorista radical para a terapia comportamental. Revista Brasileira de Terapia Comportamental e Cognitiva, 7 (1), 55-66.

\section{Informações do Artigo}

Histórico do artigo:

Submetido em: 26/06/2015

Primeira decisão editorial: 30/07/2015

Aceito em: 09/09/2015

Editor Associado: Felipe Leite 